\title{
LOW-LEVEL GAS PROPORTIONAL COUNTING IN AN UNDERGROUND LABORATORY
}

\section{H H LOOSLI, MARTIN HEIMANN and HANS OESCHGER}

Physics Institute, University of Bern, Sidlerstrasse 5, CH-3012 Bern, Switzerland

\begin{abstract}
Results of measurements in an underground laboratory, $70 \mathrm{~m}$ of water equivalent below surface, are given. Background values of proportional gas counters with volumes between $16 \mathrm{cc}$ and $1.5 \mathrm{~L}$ are lower by a factor of $2-4.5$ compared to the values in the previously used laboratory $(7 \mathrm{~m}$ w.e.). High counting gas pressures, up to 5 at $\mathrm{CH}_{4}$ and up to 36 at $\mathrm{P}-10$, enable the use of relatively small counters with correspondingly small background contributions from the walls. A separation of the residual background into different components is attempted, distinguishing a pressure dependent volume effect and surface correlated contributions. It can be shown that the selection of radioactively pure counter construction material is very important for a good low level counting system.
\end{abstract}

\section{INTRODUCTION}

Until now the use of radioisotopes in environmental studies has mainly been restricted to isotopes like ${ }^{3} \mathrm{H}$ and ${ }^{14} \mathrm{C}$ which can be measured relatively easily at environmental levels. Other radioisotopes or small samples of ${ }^{3} \mathrm{H}$ and ${ }^{14} \mathrm{C}$ promise to yield important information, but are beyond the sensitivity range of presently used low level counting techniques. 'The development of especially sensitive measuring techniques is, therefore, highly desirable. This is demonstrated by the development of mass and charge spectroscopy using accelerators. Element and probably later on, isotope-specific laser spectroscopy are other promising prospects for high sensitivity measurements of very few atoms. Low level gas counting during the last decades has been well-developed and will play an important role for measurements with a more routine character. For example, noble gas isotopes like ${ }^{39} \mathrm{Ar},{ }^{37} \mathrm{Ar}$, and, at environmental levels, ${ }^{85} \mathrm{Kr}$, until now, could only be measured by gas proportional counting. Stable low background gas counting systems, therefore, will remain a necessity in the foreseeable future.

It may also be interesting to investigate the limits of background reduction. We had the opportunity to combine measurements in an underground laboratory with special developments of low level proportional counters. Counters were constructed that could be filled to high gas pressures to improve volume to surface ratio which yields lower background values.

The availability of two laboratories with different muon fluxes facilitated the attempt to disentangle the different background components of our proportional counters of different size. This analysis was undertaken to obtain information on shielding and construction principles for very low background counting systems.

Also investigated was how the backgrounds of counters with internal anticoincidence systems (Oeschger, 1963), constructed for the measurement of radioisotopes emitting $\beta$-particles at low energies, like ${ }^{3} \mathrm{H}$ and ${ }^{14} \mathrm{C}$ or X-rays, compare with the backgrounds of recently developed small high pressure gas counters. 
Background of gas proportional counters in our underground laboratory

In 1975 we moved our counting system from the basement of the Institute $(\sim 7 \mathrm{~m}$ water equivalent shielding) to a new underground laboratory $(\sim 70 \mathrm{~m}$ w.e. below surface) in the same building. The $40 \mathrm{~cm}$ thick walls of this laboratory were constructed from specially selected concrete (Pulfer, 1974). The selection is based on $\gamma$-measurements with a $\mathrm{NaJ}$ crystal in the energy interval 0.1 to $3 \mathrm{MeV}$. We decided to use serpentine gravel and sand and Danish cement as concrete components. The $\gamma$ measurements showed reduction factors of $>30$ for sand and gravel and about 4 for the cement, compared with the concrete components commonly used in our area.

The muon flux decreased by a factor of 11 in agreement with expectation. According to the literature, the muon stop rate drops by about a factor of 40 . The nucleonic component of the cosmic radiation is absorbed much stronger than the muon component and should be negligible. For the $\gamma$ - and n-fluxes in a $10 \mathrm{~cm}$ shield in the underground laboratory, a considerable reduction was observed, when compared to the fluxes in the old laboratory. For the $\gamma$-counting rate in the energy interval between 239 and $1460 \mathrm{keV}$, a reduction factor of about 6 was measured with a $60 \mathrm{cc}$ GeLi detector. Despite the strong reduction of the nucleonic component of the cosmic radiation, there are still neutrons from muon capture reactions and from spontaneous fission and $\alpha, \mathrm{n}$ reactions in the surrounding sandstone. A reduction factor of about 8 was observed for the n-flux with a $\mathrm{BF}_{3}$ counter and a He-3-counter. The real reduction factors for the $\gamma$ - and n-fluxes may be higher than the observed values since the background contribution (from the construction material) of the detectors themselves are unknown.

TABLE 1

Background values of gas proportional counters in our underground laboratory

\begin{tabular}{|c|c|c|c|c|c|c|}
\hline $\begin{array}{l}\text { Material } \\
\text { type }\end{array}$ & $\begin{array}{l}\text { Volume } \\
\quad \text { (cc) }\end{array}$ & $\begin{array}{l}\text { Pressure } \\
\quad \text { (at) }\end{array}$ & Gas* & $\begin{array}{l}\text { Background } \\
\text { (cpm) }\end{array}$ & $\begin{array}{c}\mathrm{S}^{2} / \mathrm{BG} \\
\left(\text { for }{ }^{38} \mathrm{Ar}\right)^{* *}\end{array}$ & $\begin{array}{c}\text { Sample } \\
\text { volume }(\mathrm{L})\end{array}$ \\
\hline $\mathrm{Cu}$ & 16 & 28 & P-10 & 0.027 & 0.044 & 0.45 \\
\hline $\mathrm{Cu}$ & 22 & 17 & P-10 & 0.03 & 0.024 & 0.37 \\
\hline $\mathrm{Cu}-1$ & 50 & 36 & P. 5 & 0.08 & 0.23 & 1.8 \\
\hline $\mathrm{Cu}-1$ & 50 & 15 & P- 5 & 0.06 & 0.067 & 0.75 \\
\hline $\mathrm{Cu}-2$ & 100 & 19 & P- 5 & 0.11 & 0.28 & 1.9 \\
\hline $\mathrm{Cu}-2$ & 100 & 8.9 & P- 5 & 0.09 & 0.076 & 0.9 \\
\hline Plexi & 100 & 17 & P- 5 & 0.12 & 0.13 & 1.85 \\
\hline Plexi & 1000 & 4.5 & P. 5 & 0.5 & $\sim 0.4$ & 4.5 \\
\hline $\mathrm{Cu}$ & 1000 & 4.5 & $\mathrm{CH}_{4}$ & 0.5 & - & - \\
\hline Int $\mathrm{AK}$ foil $\dagger$ & 1500 & 1.6 & $\mathrm{CH}_{4}$ & 0.3 & - & - \\
\hline Int AK wire† & 1500 & 1.3 & $\mathrm{CH}_{4}$ & 0.12 & - & - \\
\hline
\end{tabular}

* P-10 means 10 percent $\mathrm{CH}_{4}$ and 90 percent Ar.

** Specific activity of ${ }^{39} \mathrm{Ar}$ is $0.11 \pm 0.012 \mathrm{dpm} / \mathrm{L}$ argon. S: net standard count rate; BG: background count rate.

†Counter with internal anticoincidence; foil resp wire between the two volumes (Oeschger, 1963). 
TABLE 2

Comparison of background; measured and (in parenthesis) calculated values

\begin{tabular}{|c|c|c|c|c|c|}
\hline Counter & Gas & Pressure & Institute & Underground & $\begin{array}{l}\mathrm{S}_{\alpha \beta}\left(\times 10^{-1}\right. \\
\left.\mathrm{cpm} / \mathrm{cm}^{2}\right)\end{array}$ \\
\hline $22 \mathrm{cc} \mathrm{Cu}$ & P-10 & 5 at & $0.11(0.10)$ & $0.023(0.023)$ & 2.3 \\
\hline 20cc Delrin & P-10 & 5 at & $0.10(0.126)$ & $0.045(0.045)$ & 6.3 \\
\hline 100cc Plexi & P- 5 & 17 at & $0.32(0.46)$ & $0.12(0.12)$ & 4 \\
\hline 1000cc Plexi & P- 2 & 4.6 at & $1.70(1.74)$ & $0.5 \quad(0.47)$ & 3.9 \\
\hline int $\mathrm{AK}$ foil & $\mathrm{CH}_{4}$ & 1.6 at & $1.25(1.02)$ & $0.20 \quad(0.30)$ & 2.3 \\
\hline int $\mathrm{AK}$ wires & $\mathrm{CH}_{4}$ & 1.2 at & $0.40(0.76)$ & $0.115(0.115)$ & 0.5 \\
\hline
\end{tabular}

Measured integral background values of different counters are given in tables 1 and 2 and in figure 1 . The counters described by Oeschger (1963) (with foil for ${ }^{14} \mathrm{C}$ and wires for ${ }^{3} \mathrm{H}$ ) have an internal anticoincidence system; the others are operated in an external guard counter with a $2 \mathrm{~cm}$ thick pure old lead shield between guard and main counter. Most measurements were carried out in a $10 \mathrm{~cm}$ shield of lead from a Swedish mine (Boliden) or from an old Dutch shipwreck. The volume of the counters used varies by two orders of magnitude; the counters were filled with gas at pressures up to 36 atmospheres. As filling gas, argon- $\mathrm{CH}_{4}$ mixtures (usually 5 or 10 percent $\mathrm{CH}_{4}$ ) were used in the high pressure counters, whereas ${ }^{14} \mathrm{C}$ and ${ }^{3} \mathrm{H}$ are routinely measured with $\mathrm{CH}_{4}$ gas.

Figure 1 and table 2 show that, in the underground laboratory, the background was lower by a factor of 2-4.5 than in the Institute laboratory. A similar reduction was also observed by Reidar Nydal and Knut Lövseth (pers commun) who, during the Radiocarbon Conference, tested their $\mathrm{CO}_{2}$ counter of $1.5 \mathrm{~L}$ volume in our underground laboratory.

Table 1 gives the lowest background values obtained up to now for the counting systems presently in operation. As a threshold for the pulses, a value of a few millivolts at the output of the counters was used and, by external calibration with $\gamma$-sources, the gas multiplication was kept constant in the argon- $\mathrm{CH}_{4}$ filled counters. Nevertheless, the background values can only be compared to each other within some uncertainty because the energy spectra of the background measurements showed, for some counters, irregularities especially at low energies.

A comparison of our background values with those obtained in other laboratories is difficult. Our high pressure counters are mainly used for ${ }^{39} \mathrm{Ar}$ activity measurements, whereas other laboratories concentrate on ${ }^{14} \mathrm{C}$ or ${ }^{3} \mathrm{H}$ measurements. Since the specific activity of ${ }^{39} \mathrm{Ar}$ is about 50 times smaller than that of ${ }^{14} \mathrm{C}$ in $\mathrm{CH}_{4}$, the figure of merit (FOM) cannot be used for a comparison. Values for the ratio of background to sample volume (counter volume times pressure) at normal temperature are more comparable. The lowest values for this parameter obtained in our underground laboratory are:

$0.06 \mathrm{cpm} / \mathrm{L}$ gas for the,$"$ 16cc Cu counter, 28 at P-10
$0.08, \quad$,, 17 at P-10 


$$
\begin{aligned}
& 0.044 \quad, \quad, \quad, \quad, \quad 50 \mathrm{cc} \quad, \quad, \quad, 36 \text { at P-5 } \\
& 0.06 \quad " \quad, \quad, \quad, 100 c c \quad " \quad, \quad, 19 \text { at P-5 } \\
& 0.11 \quad, \quad " \quad, 1000 \mathrm{cc}, \quad ", 4.5 \text { at } \mathrm{CH}_{4} \\
& 0.13 \quad " \quad " \quad, \quad, \quad 1.5 \mathrm{~L} \text {, with int } \mathrm{AK} \text { counter, } 1.6 \text { at } \mathrm{CH}_{4} \\
& 0.11 \text { " " " " Nydal ," } 2 \text { at } \mathrm{CO}_{2}
\end{aligned}
$$

In other laboratories, eg, the following values were measured:

$0.2 \mathrm{cpm} / \mathrm{L}$ gas for $0.8-4.5 \mathrm{~L}$ counters with 3 at $\mathrm{CO}_{2}$

(Stuiver, Robinson, and Yang, 1976)

$$
\begin{aligned}
& 0.2 " \quad " \quad " 0.6-1.8 \mathrm{~L} \text { counters with } 2 \text { at } \mathrm{CO}_{2} \\
& \text { (Nydal, Gulliksen, and Lövseth, 1975) }
\end{aligned}
$$

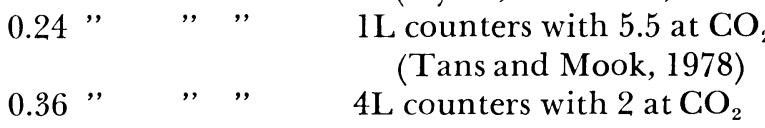

$$
\begin{aligned}
& \text { (Schoch and others, 1980) }
\end{aligned}
$$

These values can only be used for a rough comparison of counting systems, because not considered are, eg, losses of gas in the filling line and decreasing counting yield due to increasing influence of end effects for smaller counters. There might also be an objection to this comparison in that the counters with the lowest ratio of background to sample volume are those using Ar at a very high pressure. On the other hand, it is demonstrated that, in an underground laboratory, by operating relatively small counters at high pressure, background values that are significantly below those obtained by other laboratories can be measured.

In table 1 , the values for $\mathrm{S}^{2} / \mathrm{BG}$, which are proportional to the figure of merit, are given for the counters used for ${ }^{39} \mathrm{Ar}$ measurements. The measurement of this isotope with a low specific activity of about 0.11 $\mathrm{dpm} / \mathrm{L}$ argon needs extreme low level counting systems. Earlier measurements were performed in the $1 \mathrm{~L}$ Plexi counter with $4.5 \mathrm{~L}$ sample volume. For applications in ice and groundwater dating, the amount of sample had to be reduced. The second generation of counters $(100 \mathrm{cc}$ and $50 \mathrm{cc}$ ) used an amount of only about $2 \mathrm{~L}$ of argon. Due to the use of 10 to 20 times smaller counters with correspondingly higher pressures, the background value could be reduced considerably. The figure of merit, therefore, is only smaller by about a factor of 1.6 , although the square of the standard count rate decreased by about a factor of 6 . An even smaller third generation of ${ }^{39} \mathrm{Ar}$ counters ( 16 and $22 \mathrm{cc}$ ) was constructed recently; it is supposed to be used for ${ }^{39} \mathrm{Ar}$ dating of ocean water. Although the backgrounds of these counters are even lower, the figure of merit is now also reduced considerably, partly because of the dead volumes of the valve and connections that become relatively more important. This effect can be partly corrected for by using counters with higher ratio of length to diameter to increase the counting efficiency (Cu 2, 16cc). However, this leads to an increase of the surface related background contributions. 


\section{Background Reduction in Underground Laboratory}

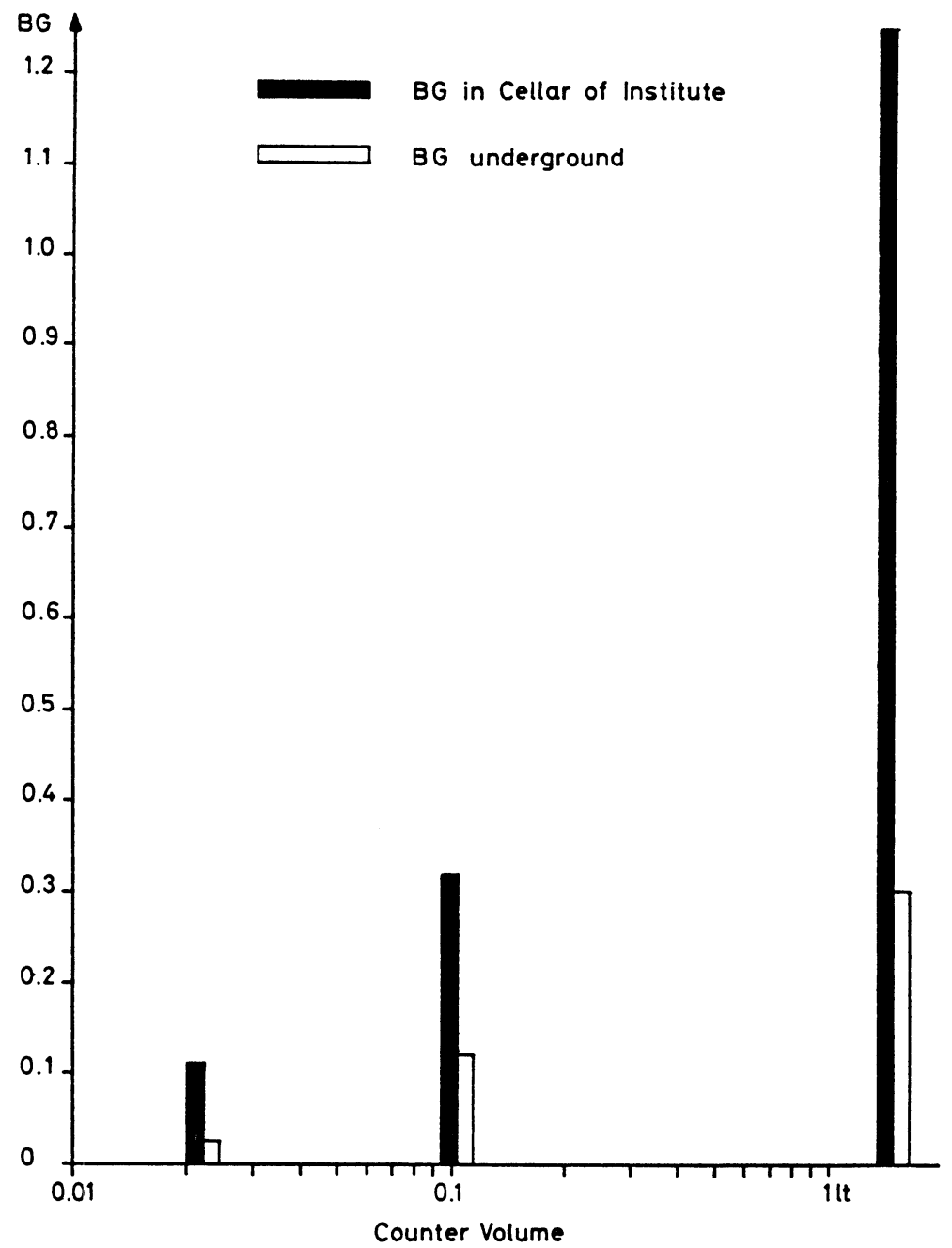

Fig 1. Background reduction in an underground laboratory. For different counters reduction factors of $2-4.5$ could be obtained by moving underground. As examples, background values are given for three counters: a 22cc Cu counter filled with 5 at P-10, a 100cc Plexi counter filled with 17 at P-5, and a foil counter with internal anticoincidence for ${ }^{14} \mathrm{C}$ filled with 1.6 at $\mathbf{C H}_{4}$. 


\section{Estimation of the relative contributions of different background components}

The availability of two laboratories with entirely different muon fluxes enabled us to attempt a separation of the background into the following four components:

$-\alpha$ and $\beta$ particles from the inner counter wall; flux is $S_{\alpha \beta}$ in $\mathrm{cpm} / \mathrm{cm}^{2}$ - a contribution proportional to the muon flux $\phi$, rate a. This component includes non-cancelled secondaries from the end parts of the shield and non-cancelled muons by the anticoincidence system.

- recoil nuclei from collisions with neutrons; mainly in the $\mathrm{CH}_{4}$ component of the filling; source strength $S_{\mathrm{np}}$ in $\mathrm{cpm} / \mathrm{g}$.

$-\gamma$-induced secondary electrons, created in the counting gas or in the wall; source strength $S_{\gamma e}$ in $\mathrm{cpm} / \mathrm{g}$.

The background $\mathrm{BG}$ in $\mathrm{cpm}$, then, can be approximated by the formula

$\mathrm{BG}=\mathrm{S}_{a \beta} \cdot \mathrm{O}+\mathrm{a} \cdot \phi+\mathrm{S}_{\mathrm{np}} \cdot\left(\mathrm{V} \rho_{\mathrm{CH}_{4}}+\frac{\mathrm{O} \cdot \overline{\mathrm{R}}_{\mathrm{p}}}{4}\right)+\mathrm{S}_{\gamma \mathrm{e}} \cdot\left(\mathrm{V} \rho_{\mathrm{tot}}+\frac{\mathrm{O} \cdot \overline{\mathrm{R}}_{\mathrm{e}}}{4}\right)$

with $\mathrm{O}=$ surface in $\mathrm{cm}^{2}$ of counter, $\mathrm{V}=$ volume in $\mathrm{cm}^{3}, \rho=$ density of counting gas in $\mathrm{g} / \mathrm{cm}^{3}$ and $\overline{\mathrm{R}}_{\mathrm{p}}$ and $\overline{\mathrm{R}}_{\mathrm{e}}=$ average range of recoil nuclei and secondary electrons, respectively.

The volume-correlated contribution could be determined by measuring the dependence of the background on the gas filling pressure. In tables 1 and 2 examples for two different pressures can be found for the $22 \mathrm{cc}$, the 50cc, and the $\mathrm{Cu}-2100 \mathrm{cc}$ counters. For these measurements, the gas multiplication was kept constant. Background values for different filling gas compositions $\left(\mathrm{Ar}, \mathrm{CH}_{4}\right)$ yielded additional information. Also, the measured reduction factors for neutrons (factor 8) and for $\gamma$-rays (factor 6) were used. Since unidentical lead shields were used in the two laboratories and the electronic sensitivity was not equal for all counters, the comparison can give only the order of magnitude of the effects. Nevertheless, agreement with earlier published conclusions (Oeschger and Loosli, 1975; Oeschger and Wahlen, 1975) is satisfactory, although more and improved counters are used by now.

Based on these results and factors, a set of parameters can be determined for the old and the underground laboratory (see table 3). The values for $S_{\alpha \beta}$ for each individual counter was determined from the background values measured underground (see table 2). Table 2

TABLE 3

Set of parameters adopted for background analysis

\begin{tabular}{llll}
\hline \multicolumn{2}{c}{ Parameter } & \multicolumn{1}{c}{ Institute } & Underground \\
\hline $\mathrm{a}$ & & $3.2 \cdot 10^{-3}$ & $3.2 \cdot 10^{-3}$ \\
$\mathrm{~S}_{\mathrm{np}}$ & $(\mathrm{cpm} / \mathrm{g})$ & 0.048 & 0.006 \\
$\mathrm{~S}_{\gamma \mathrm{e}}$ & $(\mathrm{cpm} / \mathrm{g})$ & 0.054 & 0.009 \\
$\overline{\mathrm{R}}_{\mathrm{p}}$ & $\left(\mathrm{mg} / \mathrm{cm}^{2}\right)$ & 2 & 2 \\
$\overline{\mathrm{R}}_{\mathrm{e}}$ & $\left(\mathrm{mg} / \mathrm{cm}^{2}\right)$ & 70 & 80 \\
\hline
\end{tabular}




\section{Background Components (calculated)}

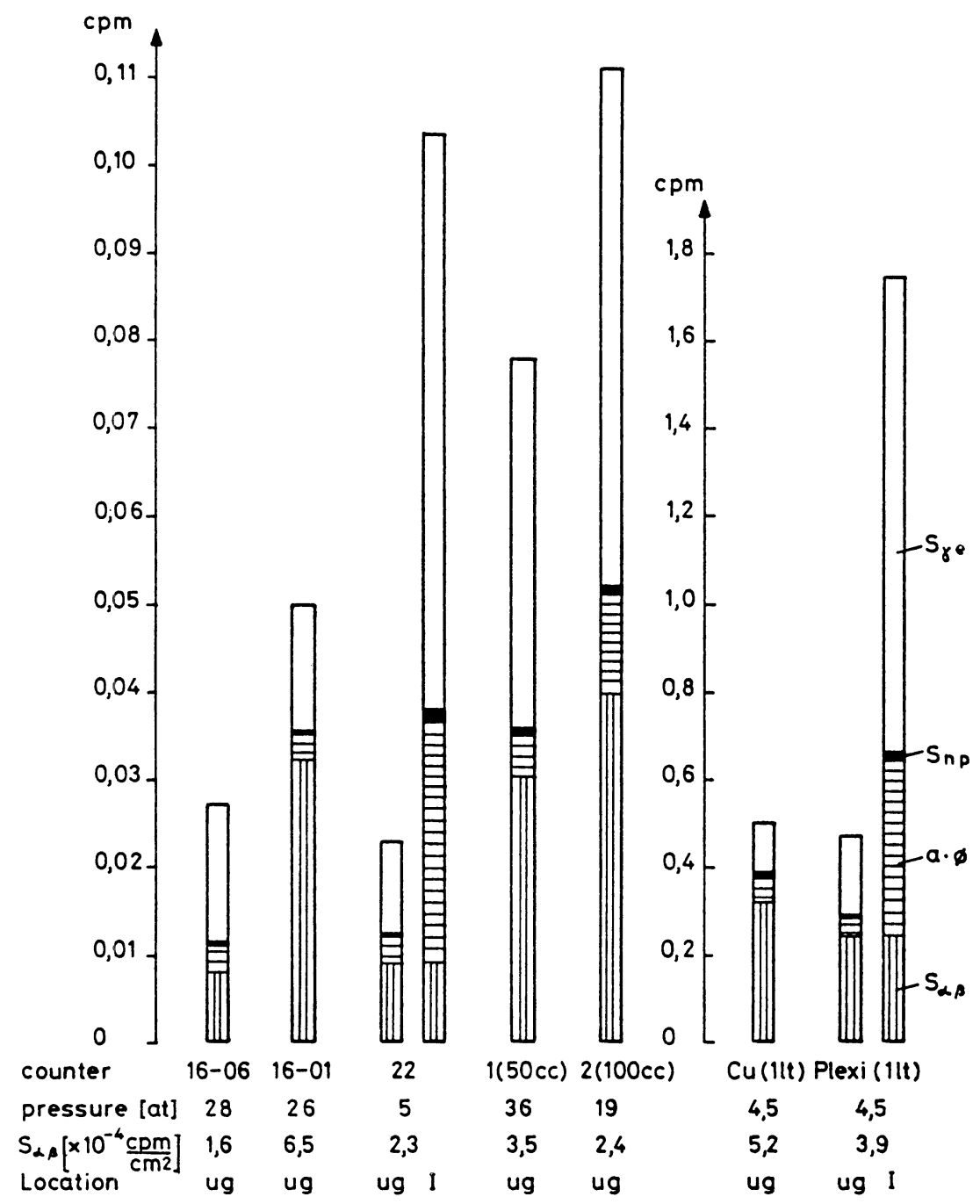

Fig 2. Calculated background components. For proportional counters with different volumes $(16,22,50,100,1000 \mathrm{cc})$ and different filling gas pressures, the estimated background components are given for our underground laboratory (ug) and the laboratory in the Institute $(\mathrm{I}) . \mathrm{S}_{\gamma \mathrm{e}}$ is the component induced by $\gamma$-rays in the counter volume or in the wall: $S_{m p}$ is the component induced by neutrons, $a \cdot \phi$ is the component proportional to the muon flux, and $S_{\alpha \beta}$ is the component from self-activity in the counter wall. All counters are constructed from copper with the exception of the $1 \mathrm{~L}$ Plexi counter. For discussion of the estimated parts, see text. 
shows that the measured and calculated integral background values agree for most of the counters within about 20 percent, especially for the high pressure argon counters. The counters with internal anticoincidence show a somewhat larger uncertainty, but this might be due to their different anticoincidence system.

With the set of parameters adopted, the background components of the different counters can be estimated for the Institute and for the underground laboratory. They are plotted in figure 2 for some of the counters together with values for counter size, filling pressure and adopted surface wall activity. It can be concluded that, especially in the underground laboratory (eg, for the 50cc, $1 \mathrm{~L} \mathrm{Cu}$ and $1 \mathrm{~L}$ Plexi counters), the wall activity contributes a large fraction, up to 50 percent, to the background. Counters 16-06 and 16-01 demonstrate that the selfactivity of counter construction materials like copper may change from piece to piece. The neutron components (especially of the argon- $\mathrm{CH}_{4}$ counters) are negligible. It also follows that, by going underground, mainly the fractions proportional to the muon flux $\phi$ and the $\gamma$ included component are significantly reduced (see counters 22cc and IL Plexi). The ratio of volume to surface contribution induced by $\gamma$-rays depends on the filling pressure; for relatively small pressures both contributions are about equal, whereas, with high pressures, the volume components may dominate (eg, Cu l-counter).

The formula given above can be simplified for a quick and rough estimate of the smallest practically possible background value. For average values of our parameters our underground laboratory yields:

$$
\mathrm{BG}=4 \cdot 10^{-4} \frac{\mathrm{cpm}}{\mathrm{cm}^{2}} \cdot \mathrm{O}+0.01 \mathrm{cpm} / \mathrm{g} \cdot \mathrm{V} \cdot \rho
$$

where we have used the following parameters: $S_{\alpha \beta}=2 \cdot 10^{-4} \mathrm{cpm} / \mathrm{cm}^{2}$, $\mathrm{a}=3.2 \cdot 10^{-3}$ and $\phi=0.02 \mathrm{cpm} / \mathrm{cm}^{2} \cdot \mathrm{O}$.

\section{CONCLUSION}

Our results show that background values of gas proportional counters can be lowered considerably by measuring underground. Furthermore, reduction of the counter volume with corresponding increased pressure of filling gas enables a significant reduction of the background for a given sample amount.

Construction materials must be selected very carefully:

- we had good experience with Cu qualities and with Plexiglas or Delrin for counter wall construction

— special lead qualities can be found with considerable lower self-activity than in commercial lead

- it is advantageous if the components of concrete in an underground laboratory are low in radioactivity, especially if $\gamma$-sensitive proportional gases are used (high $\mathrm{Z}$ ). 
Counters constructed with internal anticoincidence are still an excellent way to obtain a good low level system for low $\beta$-energy measurements.

Our attempt to separate an integral background value into several components looks promising. For our counters with volumes between 16 and $1500 \mathrm{cc}$ agreement between measured and estimated background values could be obtained within 20 to 50 percent. Sets of parameters can be found to estimate the lowest practically possible background values.

\section{ACKNOWLEDGMENTS}

For counter construction, sample preparation, sample measurements and for drawings, we thank K Hänni, M Moell, T Riesen, U Schotterer, and P Wittwer. The research project is supported by the Swiss National Foundation.

\section{REFERENCES}

Nydal, Reidar, Gulliksen, Steinar, and Lövseth, Knut, 1975, Proportional counters and shielding for low level gas counting, in Internatl conf on low radioactivity measurements and applications, High Tatras: $\mathrm{p}$ 77-84.

Oeschger, Hans, 1963, Low-level counting methods, in Radiocarbon dating: IAEA, Vienna, p 13-34.

Oeschger, Hans and Loosli, H H, 1975, New developments in sampling and low level counting of natural radioactivity, in Internatl conf on low radioactivity measurements and applications, High Tatras: $p$ 13-22.

Oeschger, Hans and Wahlen, Martin, 1975, Low level counting techniques: Ann Rev Nuclear Science, v 25, p 423-463.

Pulfer, Peter, 1974, Grundlagen zum Bau eines Tieflabors zur Messung schwach radioaktiver Proben: Lizentiatsarbeit Univ Bern, unpub.

Schoch, Hilla, Bruns, Michael, Münnich, K O, and Münnich, Marianne, 1989, A multicounter system for high precision ${ }^{14} \mathrm{C}$ measurements, in Stuiver, Minze and $\mathrm{Kra}$, Renee, eds, Internatl radiocarbon conf, 10th, Proc: Radiocarbon, v 22, no. 2, p 442-447.

Stuiver, Minze, Robinson, S W, and Yang, I C, 1979 , ${ }^{14} \mathrm{C}$ dating up to 60,000 years BP with high efficiency proportional counters, in Berger, Rainer and Suess, H E, eds, Radiocarbon dating, Internatl radiocarbon conf, 9th, Proc: Berkeley/Los Angeles, Univ California Press, p 202-215.

Tans, P P and Mook, W G, 1979, Design, construction and calibration of a high accuracy carbon-14 counting set up: Radiocarbon, v 21, p 22-40. 